\title{
KUALITAS HIDUP PASIEN SKIZOFRENIA DIPERSEPSIKAN MELALUI STIGMA DIRI
}

\author{
Ice Yulia Wardani*, Fajar Apriliana Dewi \\ Fakultas Ilmu Keperawatan Universitas Indonesia, Depok 16424, Indonesia \\ *E-mail: iceyulia1@yahoo.com
}

\begin{abstract}
Abstrak
Skizofrenia merupakan sekumpulan gejala atau sindrom yang dapat menyebabkan masalah kejiwaan yang sangat serius. Stigma diri muncul akibat efek negatif penilaian orang lain terhadap pasien Skizofrenia sehingga mengakibatkan penurunan kemampuan kerja, fungsi sosial, harga diri, dan harapan. Kualitas hidup pasien Skizofrenia erat kaitannya dengan disabilitas yang dialaminya berupa perubahan kognitif dan persepsi dalam menjalani kehidupan. Penelitian ini bertujuan untuk mengidentifikasi kualitas hidup pasien skizofrenia melalui stigma diri. Desain penelitian ini adalah descriptive corelative dengan pendekatan cross sectional, sampel 92 responden yang dipilih menggunakan teknik consecutive sampling. Analisis uji statistik menggunakan correlation test. Hasil dari penelitian adalah ada hubungan antara stigma diri dengan kualitas hidup pasien Skizofrenia dengan korelasi negatif $(\mathrm{r}=-0,568, \mathrm{p}=0,00)$. Level stigma diri termasuk kedalam klasifikasi stigma tinggi dan klasifikasi kualitas hidup yang rendah. Penelitian ini merekomendasikan pelaksanaan intervensi keperawatan yang berorientasi pada pasien berupa pencegahan stigma negatif dan peningkatan kualitas hidup.
\end{abstract}

Kata kunci: kualitas hidup, Skizofrenia, stigma diri

Abstract

Quality of Life Schizophrenia Patients Treated Through Self Stigma. Schizophrenia is a syndrome that could induce seriously psychology problems. Self stigma can induce because of consequence of negative stereotype in patients with Schizophrenia with the result that diminished ability to work, social function, self-esteem and hope. Quality of life in patients with Schizophrenia related to disability because of impaired cognitive and perception in their life. This study was conducted to correlation between self stigmawith quality of life in patients Schizophrenia. Methodology use descriptive correlative with cross sectional study, used 92 patients with a diagnosis of Schizophrenia and used consecutive sampling. Statistical analysis test using correlation test. Result this study, there is significance correlation between self stigma and quality of life $(p=0.00<0.005)(r=-0.865)$. The level of self stigma of patients with schizophrenia was determined to be high, and the self stigma had a negative impact on the quality of life. This study recommends the implementation of patient oriented nursing interventions in the form of prevention of negative stigma and improvement of quality of life

Keywords: internalized stigma, quality of life, Schizophrenia

\section{Pendahuluan}

Gangguan jiwa merupakan respon maladaptif terhadap stressor yang muncul dari dalam dan luar individu, sehingga mengakibatkan perubahan pola pikir, persepsi, tingkah laku dan perasaan yang berbeda dengan norma atau budaya yang ada, serta gangguan pada fungsi fisik dan sosial yang menimbulkan gejala kesulitan dalam berhubungan sosial dan kemampuan kerja (Townsend, 2011). Salah satu diagnosis gangguan jiwa adalah Skizofrenia. Skizofrenia adalah gangguan jiwa dimana terjadi gangguan neurobiologi dengan karakteristik kekacauan pada pola pikir dan isi pikir, halusinasi dan delusi, serta kekacauan pada proses persepsi, afek dan perilaku sosialnya (Kopelowicz, Liberman \& Wallace, 2003). 
Prevalensi Skizofrenia penduduk dunia sekitar $1,1 \%$, jika jumlah penuduk dunia menurut PBB pada tahun 2012 mencapai 7,2 milyar maka ada sekitar 72 juta penduduk dunia mengalami gangguan jiwa dan $40 \%$ dari mereka dilaporkan tidak mendapatkan terapi kejiwaan apapun yang berdampak pada pemasungan, kekerasan, dan pengangguran (National Advisory Mental Health Council, 2001: National Institute of Mental Health, 2008: Shives, 2012). Prevalensi Skizofrenia di Amerika Serikat sebesar 1,5\% dengan umur hidup sebesar $0,7 \%$ yang didapat dari hasil interview (WHO, 2011).

Gejala residu muncul akibat ada stressor dari lingkungan dan kurangnya dukungan sosial pada pasien Skizofrenia (Lysaker, Davis, Warman, Strasburger, \& Beattie, 2007). Dukungan sosial yang baik secara psikologis berhubungan dengan peningkatan motivasi dan ekspresi senang pada pasien Skizofrenia, sedangkan dukungan sosial yang kurang berdampak pada rendahnya fungsi sosial (Sibitz, et al., 2011). Staring, Van der Gaag, Van den Berge, Duivenvoorden, dan Mulder (2009) mengatakan bahwa adanya hubungan antara harga diri rendah pasien Skizofrenia dengan perlakuan dari lingkungan sosial yang berakibat terstigmanya pasien Skizofrenia.

Mashiach-Eizenberg, Hasson-Ohayon, Yanos, Lysaker, dan Roe (2013) menyebutkan Skizofrenia dengan stigma diri negatif memunculkan harapan (hope) yang rendah, mengakibatkan rendahnya harga diri dan kemampuan diri sehingga secara langsung berhubungan dengan proses pemulihan berupa penurunan kesadaran atau tilik diri terhadap penyakit yang selanjutnya sangat berdampak pada kualitas hidup pasien Skizofrenia. Penelitian Sibitz, et al. (2011) tentang pengaruh social network, stigma diri dan dukungan dengan kualitas hidup pasien Skizofrenia di Austria, menyatakan ada hubungan yang signifikan antara stigma diri dengan kualitas hidup pasien Skizofrenia dengan arah hubungan negatif, apabila stigma diri tinggi maka kualitas hidup rendah.
Menurut Da silva, Mason, Abelha, Lovisi, dan Cavalcanti (2011) kualitas hidup mencakup beberapa hal meliputi, kesehatan fisik, kesehatan mental, tingkat ketergantungan, kepercayaan individu dan hubungan dengan lingkungan sekitarnya yang diwujudkan dalam semangat untuk memperoleh sumber penghasilan, memelihara diri sendiri dan kemandirian yang disesuaikan dengan usia. Pengkajian kualitas hidup yang berhubungan dengan gangguan jiwa berfokus pada gejala, penurunan dan ketidakmampuan individu yang berdampak pada gangguan jiwa berat dari kesengsaraan jangka panjang dan penyakit yang membuat disable seperti Skizofrenia (Gigantesco \& Giuliani, 2011). Berdasarkan uraian tersebut maka pertanyaan penelitian ini adalah "Bagaimanakah hubungan antara stigma diri dengan kualitas hidup pada pasien Skizofrenia di rumah sakit jiwa?"

\section{Metode}

Desain penelitian menggunakan descriptive correlative dengan metode cross sectional. Jumlah responden sebanyak 92 dengan menggunakan teknik pengambilan sampel consecutive sampling. Responden merupakan pasien poli psikiatri salah satu rumah sakit jiwa di Jakarta. Kriteria inklusi responden, yaitu: (a) Pasien Skizofrenia sesuai DSM IV-TR (rekomendasi psikiater penanggungjawab pasien) dan menjalani pengobatan di poliklinik rawat jalan secara teratur minimal satu kali dalam satu bulan; (b) Dapat membaca dan menulis; (c) Bersedia dan mampu berpartisipasi dalam penelitian; (d) Usia 20-60 tahun; (e) Tidak ketergantungan alkohol dan obat terlarang; (f) Pasien pada masa stabil minimal 4 bulan setelah rawat inap.

Instrumen stigma diri yang digunakan Internalized Stigma Mental Illness menurut Boyd, Adler, Otilingam dan Peters (2013), terdiri dari 29 pernyataan dengan skala likert dengan nilai 1-4. Kualitas hidup menggunakan WHOQOLBREF versi Indonesia terdiri dari 26 pertanyaan dengan skala likert 1-5. Karakteristik responden terdiri atas 9 pertanyaan. 
Prosedur pengumpulan data meliputi surat izin pengambilan data, penjelasan kepada responden, pengisian persetujuan, pengambilan data, pengolahan data, dan analisis data. Analisis data yaitu univariat (karakteristik responden, stigma diri dan kualitas hidup) dan analisis bivariat (stigma diri dan kualitas hidup) dengan uji korelasi.

\section{Hasil}

Gambaran karakteristik responden yang sesuai kriteria inklusi diuraikan pada Tabel 1. Berdasarkan Tabel 1, hasil analisis dari 92 responden terbanyak laki-laki $73(79,3 \%)$, menikah 72 $(78,3 \%)$, SMA $50(54,3 \%)$ tidak bekerja 69 (75\%), frekuensi rawat inap $\leq 3$ kali $79(85,9 \%)$, ada riwayat keluarga dengan menderita Skizofrenia $66(71,7 \%)$.

Berdasarkan Tabel 2, didapatkan rerata usia responden adalah 34,39 tahun $(\mathrm{SD}=8,027)$. $\mathrm{Re}$ - rata usia onset adalah 24,03 tahun $(\mathrm{SD}=7,016)$. Rerata lamanya sakit adalah 10,48 tahun $(\mathrm{SD}=$ 7,301).

Berdasarkan Tabel 3 digambarkan bahwa komposit total stigma diri mempunyai nilai rata-rata 60,75 $(\mathrm{SD}=7,62)$ nilai terendah 38 tertinggi 74 (pada skor 24-96). Nilai rata-rata perilaku mengasingkan diri 15,29 $(\mathrm{SD}=2,72)$ nilai terendah 9 dan nilai tertinggi 21 (pada skor 6-24). Dukungan terhadap stereotip rata-rata $17,30(\mathrm{SD}=$ 2,78) nilai terendah 7 dan tertinggi 23 (pada skor 7-28). Pengalaman diskriminasi memiliki nilai rata-rata $12,66(\mathrm{SD}=1,89)$ nilai terendah 8 tertinggi 20 (pada skor 5-20). Menarik diri dari lingkungan sosial mempunyai nilai rerata 15,48 $(\mathrm{SD}=2,60)$ (pada skor 6-24) dan perlawanan stigma 14,97 $(\mathrm{SD}=2,20)$ nilai terendah 8 tertinggi 19 (pada skor 5-20).

Berdasarkan hasil analisis pada Tabel 4 dapat dijelaskan bahwa komposit rata-rata kualitas

Tabel 1. Distribusi Berdasarkan Jenis Kelamin, Status Pernikahan, Pendidikan, Status Pekerjaan, Frekuensi Rawat Inap, dan Riwayat Keluarga

\begin{tabular}{|c|c|c|}
\hline Variabel & Jumlah & Presentase $(\%)$ \\
\hline \multicolumn{3}{|l|}{ Jenis Kelamin: } \\
\hline Laki-laki & 73 & 79,3 \\
\hline Perempuan & 19 & 20,7 \\
\hline \multicolumn{3}{|l|}{ Status Pernikahan: } \\
\hline Menikah & 15 & 16,3 \\
\hline Belum Menikah & 72 & 78,3 \\
\hline Bercerai & 5 & 5,4 \\
\hline \multicolumn{3}{|l|}{ Pendidikan: } \\
\hline SD & 14 & 15,2 \\
\hline SMP & 19 & 20,7 \\
\hline SMA & 50 & 54,3 \\
\hline Perguruan Tinggi/D3 & 9 & 9,3 \\
\hline \multicolumn{3}{|l|}{ Status Pekerjaan } \\
\hline Bekerja & 29 & 25 \\
\hline Tidak berkerja & 69 & 75 \\
\hline \multicolumn{3}{|l|}{ Frekuensi Rawat Inap } \\
\hline$>3$ Kali & 13 & 14,1 \\
\hline$\leq 3$ Kali & 79 & 85,9 \\
\hline \multicolumn{3}{|l|}{ Riwayat Keluarga } \\
\hline Ada & 26 & 28,3 \\
\hline Tidak Ada & 66 & 71,7 \\
\hline
\end{tabular}


Tabel 2. Distribusi Rata-rata Berdasarkan Usia, Usia Onset, dan Lama Sakit

\begin{tabular}{lccccc}
\hline \multicolumn{1}{c}{ Variabel } & Mean & Median & SD & Min-maks & $95 \%$ CI \\
\hline Usia & 34,39 & 33,50 & 8,027 & $20-55$ & $32,73-36,05$ \\
Usia Onset & 24,03 & 23,0 & 7,016 & $9-44$ & $22,58-25,49$ \\
Lama Sakit & 10,48 & 10,0 & 7,301 & $1-32$ & $8,97-11,99$ \\
\hline
\end{tabular}

Tabel 3. Distribusi Rata-rata Stigma Diri pada Pasien Skizofrenia

\begin{tabular}{|c|c|c|c|c|c|}
\hline Variabel & Mean & Median & SD & Min-maks & $95 \% \mathrm{CI}$ \\
\hline Stigma Diri & 60,75 & 61,50 & 7,62 & $38-74$ & $59,16-62,33$ \\
\hline Perilaku Mengasingkan Diri & 15,29 & 15,27 & 2,72 & $9-21$ & $14,72-15,85$ \\
\hline Dukungan terhadap Stereotip & 17,30 & 17,00 & 2,78 & $7-23$ & $16,72-17,88$ \\
\hline Pengalaman Diskriminasi & 12,66 & 12,50 & 1,89 & $8-20$ & $12,27-13,05$ \\
\hline $\begin{array}{l}\text { Menarik Diri dari Lingkungan } \\
\text { Sosial }\end{array}$ & 15,48 & 16,00 & 2,60 & $6-19$ & $14,94-16,02$ \\
\hline Perlawanan Stigma & 14,97 & 15,00 & 2,20 & $8-19$ & $14,52-15,43$ \\
\hline
\end{tabular}

Tabel 4. Distribusi Rata-rata Kualitas Hidup Pasien Skizofrenia

\begin{tabular}{|c|c|c|c|c|c|}
\hline Variabel & Mean & Median & SD & Min-Maks & $95 \% \mathrm{CI}$ \\
\hline Kualitas hidup & 6,92 & 59,00 & 11,60 & $44-85$ & $64,52-69,32$ \\
\hline Kualitas hidup secara umum & 2,56 & 2,50 & 0,78 & $1-5$ & $2,40-2,72$ \\
\hline $\begin{array}{l}\text { Kepuasan kesehatan fisik secara } \\
\text { umum }\end{array}$ & 2,47 & 2,00 & 0,73 & $1-5$ & $2,32-2,63$ \\
\hline Kesehatan fisik & 18,89 & 18,00 & 3,65 & $9-26$ & $18,13-19,64$ \\
\hline Psikologis & 15,46 & 15,50 & 3,72 & $9-21$ & $14,69-16,23$ \\
\hline Hubungan Sosial & 7,97 & 8,00 & 2,87 & $4-12$ & $7,62-8,32$ \\
\hline Lingkungan & 18,22 & 17,00 & 4,01 & $12-16$ & $17,39-19,06$ \\
\hline
\end{tabular}

Tabel. 5 Hubungan Antara Stigma Diri dengan Kualitas Hidup Pasien Skizofrenia

\begin{tabular}{clcc}
\hline Variabel Dependen & \multicolumn{1}{c}{ Variabel Independen } & $\mathrm{R}$ & $\mathrm{p}$ \\
\hline \multirow{3}{*}{ Stigma Diri } & Kualitas hidup & $-0,568$ & 0,000 \\
& Kualitas hidup secara umum & $-0,415$ & 0,000 \\
& Kepuasan kesehatan fisik secara umum & $-0,206$ & 0,04 \\
& Kesehatan fisik & $-0,557$ & 0,000 \\
& Psikologis & $-0,399$ & 0,000 \\
& Hubungan Sosial & $-0,536$ & 0,000 \\
& Lingkungan & $-0,518$ & 0,000 \\
\hline
\end{tabular}


hidup pasien Skizofrenia secara keseluruhan adalah $66,92(\mathrm{SD}=11,60)$ nilai terendah 44 dan tertinggi 88 (pada skor 26-130). Nilai rata-rata untuk kualitas hidup secara umum 2,56 $(\mathrm{SD}=$ 0,78 ) nilai terendah 1 dan tertinggi 5 (pada skor 1-5). Nilai rata-rata kepuasan kesehatan fisik secara umum 2,47 $(\mathrm{SD}=2,00)$ nilai terendah 1 dan tertinggi 5 (pada skor). Nilai rata-rata kesehatan fisik adalah $18,89(\mathrm{SD}=3,65)$ nilai terendah 9 dan tertinggi 26 (pada skor 7-35). Nilai rata-rata sub variabel psikologis sebesar $15,46(\mathrm{SD}=3,72)$ nilai terendah 9 dan tertinggi 21 (pada skor 6-30). Nilai rata-rata sub variabel hubungan sosial sebesar 7,97 $(\mathrm{SD}=2,87)$ nilai terendah 4 dan tertinggi 12 (pada skor 3-15). Nilai rata-rata sub variabel lingkungan sebesar $18,22(\mathrm{SD}=4,01)$ nilai terendah 12 dan tertinggi 16 (pada skor 8-40).

Hasil analisis bivariat antara stigma diri dengan sub variabel kualitas hidup didapatkan ada hubungan yang signifikan antara stigma diri (skor total) dengan kualitas hidup (skor total) $(\mathrm{p}=$ $0,000)(\mathrm{r}=-0,568)$. Ada hubungan yang signifikan antara stigma diri dengan kualitas hidup secara umum $(\mathrm{p}=0,000)(\mathrm{r}=-0,415)$. Ada hubungan yang signifikan antara stigma diri dengan kepuasan kesehatan secara umum $(\mathrm{p}=$ $0,04)(r=-0,206)$. Ada hubungan yang signifikan antara stigma diri dengan kesehatan fisik $(\mathrm{p}=0,000)(\mathrm{r}=-0,557)$. Ada hubungan yang signifikan antara stigma diri dengan psikologis $(p=0,000)(r=-0,399)$. Ada hubungan yang signifikan antara stigma diri dengan hubungan sosial $(\mathrm{p}=0,000)(\mathrm{r}=-0,536)$.

\section{Pembahasan}

Karakteristik Responden. Hasil penelitian didapatkan rerata usia pasien Skizofrenia 34,39 tahun. Penelitian ini sejalan dengan hasil penelitian oleh Üçok, Karadayi, Emiroğlu, dan Sartorius (2013) bahwa usia rata-rata pasien Skizofrenia di sebuah rumah sakit jiwa di Turki yaitu 31,49. Usia berhubungan dengan pengalaman individu terhadap stressor kehidupan, jenis sumber dukungan dan kemampuan koping serta dapat menggambarkan kemampuan pa- sien untuk menggunakan fasilitas kesehatan (Stuart, 2013).

Jenis kelamin responden yang paling banyak laki-laki 79,3\%. Hasil ini sesuai dengan Park, Bennet, Couture, dan Blanchard (2013) 71,4\% pasien Skizofrenia di Amerika yaitu laki-laki. National Institute of Mental Health (2008) dalam Shives (2012) menjelaskan Skizofrenia biasanya muncul pada laki-laki pada saat remaja akhir di usia 20 tahun atau dewasa awal atau pada usia 30 tahun. Angka kejadian relaps karena faktor ketidakpatuhan pengobatan terjadi pada laki-laki sebesar 53\% (Dewi \& Machira, 2009).

Pasien Skizofrenia yang belum menikah sebesar 78,3\%. Penelitian ini didukung MashiachEizenberg, et al. (2013) bahwa 78,2\% pasien Skizofrenia di Amerika Serikat belum menikah. Pernikahan merupakan salah satu wujud kemampuan membina hubungan interpersonal serta menggambarkan bahwa pasien Skizofrenia membutuhkan dukungan sosial dalam mewujudkan kehidupan yang berarti (Üçok, et al., 2013).

Pasien Skizofrenia berpendidikan SMA 54,3\%. Penelitian ini sejalan dengan penelitian Lv, Wolf, dan Wang (2013) bahwa pendidikan pasien Skizofrenia di China yang tamat SMA 65\%. Pendidikan merupakan sumber koping yang dapat menurunkan risiko meningkatnya stres yang berhubungan dengan gangguan jiwa atau dapat meningkatkan pemulihan (Stuart, 2013).

Pasien Skizofrenia yang tidak bekerja sebanyak 75\%. Penelitian ini didukung oleh penelitian, Üçok, et al. (2013) memaparkan proporsi pasien Skizofrenia yang tidak bekerja $62,7 \%$. Status tidak bekerja identik dengan pendapatan yang rendah merupakan stressor yang berhubungan dengan keefektifan pelayanan kesehatan jiwa pada fase akut dan relaps, kedua kondisi ini memerlukan biaya lebih untuk penanganan pasien Skizofrenia (Shives, 2011). Manfaat dari pendapatan hasil bekerja bagi pasien Skizofrenia yaitu guna faktor pencegahan dari relaps 
yang berhubungan dengan kondisi gangguan jiwa berat (Stuart, 2013).

Onset rata-rata pasien Skizofrenia adalah 24,39 tahun. Penelitian ini sejalan dengan Staring, et al. (2009) bahwa usia onset pasien Skizofrenia rata-rata 25,8 tahun. Serangan awal (onset) Skizofrenia terjadi pada masa remaja atau dewasa muda, biasanya terjadi pada usia kurang dari 30 tahun, meskipun gangguan ini mulai terdiagnosa pada saat anak-anak, sekitar $75 \%$ gejala Skizofrenia muncul pada individu berusia antara 16-25 tahun dengan prevalensi laki-laki puncak angka kejadian onset Skizofrenia antara usia 15-25 tahun dan wanita antara usia 25-35 tahun (National Institute of Mental Health, 2008; Shives, 2012).

Lama sakit rata-rata pasien Skizofrenia yaitu 10,48 tahun. Penelitian ini didukung Sibitz, et al. (2011), yang memaparkan bahwa rata-rata lama sakit pasien Skizofrenia 13,6 tahun. Lama sakit menunjukkan gambaran perjalanan penyakit dari fase akut, relaps, stabil hingga perburukan kondisi kesehatan jiwa pasien Skizofrenia (Sharaf, Ossman, \& Lachine, 2012).

Pasien Skizofrenia yang tidak memiliki riwayat keluarga dengan gangguan jiwa $71,7 \%$. Penelitian ini didukung oleh Lv, et al. (2013), yang menyatakan bahwa tidak ada riwayat keluarga pasien Skizofrenia 76,8\%. Genetik bukan satusatunya faktor penyebab Skizofrenia, teori genetik penyebab Skizofrenia $50 \%$ apabila gen tersebut dominan (Videbeck, 2011).

Gambaran Stigma Diri Pasien Skizofrenia. Stigma diri pasien Skizofrenia berada pada tingkat stigma diri tinggi yaitu perilaku mengasingkan diri, menarik diri dari lingkungan sosial, dukungan terhadap stereptip dan pengalaman diskriminasi hanya perlawanan stigma yang bersifat positif pada tingkat stigma yang rendah. Penelitian ini sesuai Hill dan Startup (2013) bahwa nilai rerata total stigma diri di Australia 74,15 (SD=14,27) berada pada rentang stigma tinggi.
Stigma diri dalam konteks kesehatan jiwa adalah suatu proses seseorang dengan gangguan jiwa berat kehilangan harapan untuk menunjukkan identitas dirinya yang ada sebelumnya kemudian menyetujui penilaian negatif orang lain terhadap dirinya (Eizenberg, et al., 2013). Tingginya tingkat stigma diri pasien Skizofrenia berhubungan positif dengan tingginya tingkat gejala negatif dan rendahnya fungsi sosial yang dimanifestasikan dalam sikap kurangnya perhatian dan harga diri yang rendah (Lysaker, et al, 2007).

Pengalaman diskriminasi dan dukungan terhadap stereotip muncul dari orang lain dan masyarakat kepada pasien Skizofrenia (Hamilton, 2012). Bentuk diskriminasi yang membuat pasien Skizofrenia sulit untuk berhubungan sosial yaitu menganggap anak kecil, tidak dapat berguna bagi diri sendiri dan masyarakat, penolakan dan pengusiran di masyarakat (Park, et al., 2013).

Proses labeling dan support system yang rendah dapat menyebabkan terjadinya stigma diri yang tinggi pada pasien Skizofrenia sehingga menyebabkan perasaan malu, berkurangnya semangat hidup, perasaan tidak berdaya dan kualitas hidup yang rendah (Eizenberg, et al., 2013). Perasaan negatif dapat menghambat proses pemulihan pasien Skizofrenia sehingga diperlukan program terapi individu yang dapat mengurangi stigma di kelompok dan komunitas guna meningkatkan kualitas hidup pasien Skizofrenia (Hill \& Startup, 2013).

Perlawanan terhadap stigma merupakan gambaran perilaku positif yang muncul dari diri pasien Skizofrenia seperti perasaan optimis, perasaan bahagia, penerimaan terhadap kondisi sakitnya, sikap penuh semangat dalam menjalani kehidupan. Kondisi ini dapat dijadikan sebagai acuan penalaksanaan pencegahan stigma diri pada pasien Skizofrenia sehingga mempercepat proses pemulihan pasien dan meningkatnya kualitas hidupnya (Yilmaz \& Okanli, 2015). 
Gambaran Kualitas Hidup Pasien Skizofrenia. Kualitas hidup terdiri dari perasaan sejahtera, kepuasan hidup dan adanya kemudahan dalam meraih kesempatan yang ada sehingga dijadikan prioritas utama dalam tujuan penatalaksanaan pasien Skizofrenia (Hayhurst, et al., 2014). Hasil penelitian kualitas hidup pasien Skizofrenia berada pada klasifikasi rendah meliputi kualitas hidup secara umum, kepuasan kesehatan fisik, kesehatan fisik, psikologis, hubungan sosial, lingkungan. Penelitian ini sesuai Adelufosi, Ogunwale, Abayomi, dan Mosanya (2013) bahwa rata-rata kualitas hidup pasien Skizofrenia di Nigeria rendah yaitu $76,19(\mathrm{SD}=10,34)$.

Beberapa faktor yang berhubungan dengan kualitas hidup pasien Skizofrenia adalah daya tilik diri, gejala depresif, kurang dukungan sosial, lamanya putus obat, gejala negatif, kecemasan, sosiodemografi, psychopathology, dan stigma diri pasien (Margariti, Plumpidis, Economou, Christodoulou, \& Papadimitriou, 2015). Tujuan utama dalam pengobatan pasien Skizofrenia adalah untuk meningkatkan kualitas hidup yang meliputi situasi yang aman, keuangan, pekerjaan dan sekolah, kemampuan melakukan aktivitas harian, kemampuan berhubungan dengan keluarga dan lingkungan sosial, mendapatkan pelayanan keperawatan yang berkesinambungan (Gomes, et al., 2014).

\section{Hubungan antara Stigma Diri dengan} Kualitas Hidup Pasien Skizofrenia. Hasil penelitian didapatkan bahwa ada hubungan antara stigma diri dengan kualitas hidup secara umum, kepuasan kesehatan fisik, kesehatan fisik, psikologis, hubungan sosial, dan lingkungan dengan arah hubungan semakin tinggi stigma diri semakin rendah kualitas hidup pasien Skizofrenia. Penelitian ini sejalan dengan penelitian yang dilakukan oleh Eizenberg, et al. (2013) bahwa ada hubungan antara stigma diri dan kualitas hidup pasien Skizofrenia dengan arah hubungan negatif, artinya semakin tinggi stigma diri semakin rendah kualitas hidup pasien Skizofrenia di Israel. Stigma diri dan kualitas hidup sering dihubungkan dengan ge- jala yang muncul, daya tilik diri, harapan dan self efficacy pada pasien Skizofrenia (Hamilton, 2012). Latar belakang pasien Skizofrenia yang mengalami gangguan kognitif dan disorganisasi berhubungan dengan penurunan kualitas hidup pasien Skizofrenia (Sigaudo, et al. 2014).

Stigma diri memengaruhi kualitas kesehatan fisik dan psikologis pasien Skizofrenia yang tergambar dari kemampuan pasien dalam memelihara tubuh dan kemampuan koping terhadap stressor yang ada (Montemagni, et al., 2014). Kodisi pasien Skizofrenia yang mengalami stigma diri yang tinggi cenderung tidak peduli dengan dirinya karena kurang semangat dalam menjalani hidup sehingga berdampak pada berkurangnya kualitas hidup terutama kesehatan fisik akibat ketidakmampuan perawatan diri (Andriyani, 2012).

Stigma diri merusak fungsi sosial pasien Skizofrenia yang tercermim dalam ketidakmampuan kualitas hidup, hubungan sosial dan lingkungan. Fungsi sosial ini termasuk didalamnya hubungan dengan orang lain, kemampuan bekerja, menjalankan aktivitas harian, dan adaptasi dengan kondisi lingkungan (Viertiö, 2011). Dukungan keluarga dan lingkungan sosial sangat diperlukan untuk meningkatkan fungsi sosial pasien Skizofrenia (Da Silva, et al., 2011).

\section{Kesimpulan}

Gambaran stigma diri tinggi adalah perilaku mengasingkan diri, menarik diri dari lingkungan sosial, dukungan terhadap stereotip dan pengalaman diskriminasi, hanya perlawanan stigma yang bersifat positif pada tingkat stigma yang rendah. Gambaran kualitas hidup pasien Skizofrenia rendah yaitu meliputi kualitas hidup secara umum, kepuasan kesehatan fisik, kesehatan fisik, psikologis, hubungan sosial, lingkungan.

Hasil penelitian menyimpulkan bahwa ada hubungan antara stigma diri (perilaku mengasingkan diri, dukungan terhadap stereotip, menarik diri dari lingkungan sosial, perlawanan stigma) 
dengan kualitas hidup (kualitas hidup secara umum, kepuasan terhadap kesehatan, kesehatan fisik, psikologis, hubungan sosial, lingkungan). Semakin tinggi stigma diri semakin rendah kualitas hidup pasien Skizofrenia. Ada hubungan antara perlawan stigma dengan kualitas hidup, dengan arah hubungan positif, semakin tinggi perlawanan stigma semakin tinggi kualitas hidup pasien Skizofrenia.

Tingginya stigma diri negatif berdampak pada lamanya proses pemulihan sehingga memengaruhi kualitas hidup pasien Skizofrenia, maka perlu intervensi keperawatan yang berorientasi pada pasien sebagai upaya pencegahan stigma negatif dan peningkatan kualitas hidup. Kualitas hidup yang tinggi menggambarkan kemampuan dan daya tilik pasien Skizofrenia yang baik, maka bagi keilmuan dan keperawatan jiwa dapat melatarbelakangi pengembangan terkait topik stigma diri dan kualitas hidup pasien Skizofrenia baik dalam perkuliahan maupun praktik klinik.

Hasil penelitian ini diharapkan sebagai landasan dasar bagi penyusunan penelitian selanjutnya terkait stigma diri negatif dan kualitas hidup pasien dengan desain multivariat yang dapat menggambarkan hubungan antara stigma diri, harga diri, daya tilik diri dan faktor-faktor yang memengaruhi proses pemulihan. Penelitian terkait kualitas hidup pasien Skizofrenia dengan menggunakan alat pengumpul data yang lebih lengkap terkait aspek kepuasan biologi, psikologi, sosial, spiritual, kemampuan ekonomi dan aktivitas kegiatan harian serta menghubungkannnya dengan harga diri dan harapan pasien Skizofrenia (AR, MK, HR).

\section{Referensi}

Adelufosi, A.O., Ogumwale, A., \& Abayomi, O., Mosanya, J.T. (2013). Sociodemographic and clinical correlates of subjective quality of life among Nigerian outpatients with schizophrenia. Psychiatry Research, 209 (3), 320-325. doi: 10.1016/j.psychres.2012.12.0 27.
Andriyani, S. (2012). Hubungan karakteristik klien skizofrenia dengan tingkat kemampuan perawatan diri di Ruang Rawat Inap Wanita Rumah Sakit Marzuki Mahdi Bogor (Skripsi, tidak dipublikasikan). Fakultas Ilmu Keperawatan Universitas Indonesia, Depok.

Da Silva, T.F.C., Mason, V., Abelha, L., Lovisi, G.M., \& Cavalcanti, M.T. (2011). Quality of life assesment of patients with spectrum disorder from psychosocial care centers. Jornal Brasileiro de Psiquiatria, 60 (2), 9198. doi: 10.1590/S0047-2085220110002000 04

Mashiach-Eizenberg, M., Hasson-Ohayon, I., Yanos, P.T., Lysaker, P.H., \& Roe, D. (2013). Internalized Stigma quality of life among persons with severe mental illness: The mediating roles of self esteem and hope. Psychiatric Research, 208 (1), 15-20. doi: 10.1016/j.psychres.2013.03.013.

Gomes, E., Bastos, T., Probst, M., Ribeiro, J.C., Silva, G., \& Rui, C. (2014). Effect of a group physical activity program on physical fittness and quality of life in individuals with schizophrenia. Mental Health and Physical Activity, 7 (3), 155-162. https://doi.org/10. 1016/j.mhpa.2014.07.002.

Gigantesco, A., \& Giuliani, M. (2011). Quality of life in mental health services with a focus on psychiatric rehabilitation practice. Ann 1st Super Sanita. 47 (4), 363-372. doi: 10.4415/ ANN_11_04_07.

Hamilton, V. (2012). An exploration of implicit associations regarding mental illness, self reported internalized stigma and their links to help seeking symptom thresholds amongst individuals experiencing depressive symptoms (Master's Thesis). Doctorate in Clinical Psychology, University of East Anglia, Norwich, UK. Retrieved from https://ueaeprints.uea.ac.uk/42449/1/2012Ha miltonVClinPsyD.pdf.

Hayhurst, K.P., Drake, R.J., Massie, J.A., Dunn G., Barnes, T.R.E., Jones, P.B., \& Lewis, S.W. (2014). Improved quality of life over one year is associated with improved adherence in 
patients with schizophrenia. European Psychiatry, 29 (3), 191-196. http:dx.doi.100. 1016/j.eurpsy.2013.03.002

Hill, K., \& Startup, M. (2012). The relationship between internalized stigma, negative symptoms and social functioning in schizophrenia: The mediating role of self-efficacy. Psychiatry Research, 206 (2-3), 151-157. doi: 10.1016/j.psychres.2012.09.056.

Kopelowicz, A., Liberman, R.P., \& Charles, J.W. (2003). Psychiatric rehabilitation for schizophrenia. International Journal of Psychology and Psychological Therapy, 3 (2), 238-298.

Lysaker, P.H., Davis, L.W., Warman, D.M., Strasburger, A., \& Beattie, N. (2007). Stigma, social function, and symptoms in Schizophrenia and Schizoaffective disorder: Associations across 6 months. Psychiatry Research, 149 (1-3), 89-95. doi: 10.1016/ j.psychres.2006.03.007.

Margariti, M., Plumpidis, D., Economou, M., Christodoulou, G.N., \& Papadimitriou, G.N. (2015). Quality of life in schizophrenia spectrum disorder: Associations with insight and psychopathology. Psychiatry Research. http:dx.doi.org/10.1016/j.psychres.2014.11.0 16.

Montemagni, C., Castagna, F., Crivelli, B., De Marzi, G., Frieri, T., Macrì, A., \& Rocca, P. (2014). Relative contributions of negative symptoms, insight, and coping strategies to quality of life in stable schizophrenia. Psychiatry Research, 220 (1-2), 102-111. doi: 10.1016/j.psychres.2014.07.019.

Park, S.G, Bennett, M.E., Couture, S.M., \& Blanchard, J.J. (2013). Internalized stigma in schizophrenia: Relations with dysfunctional attitudes, symptoms and quality of life. Psychiatry Res, 205 (1-2), 43-47. doi: 10.1016/j.psychres.2012.08.040.

Dewi, R., \& Machira, C.R. (2009). Riwayat Gangguan Jiwa pada Keluarga dengan Kekambuhan Pasien Skizofrenia di RSUP dr Sarjito Yogyakarta. Berita Kedokteran
Masyarakat, 25 (4), 176-179. https://doi.org/ 10.22146/bkm.3551.

Sharaf, A.Y., Ossman, L.H., \& Lachine, O.A. (2012). A cross-sectional study of the relationships between illness insight, internalized stigma, and suicide risk in individuals with Schizophrenia. International Journal of Nursing Studies, 49 (12), 1512-1520. doi: 10.1016/j.ijnurstu.2012.08.006

Shives, L.R. (2012). Basic concepts of psychiatricmental health nursing (8th Ed.). Florida: Wolters Kluwer, Lippincott Williams \& Wilkins.

Sigaudo, M., Crivelli, B., Castagna, F., Giugiario, M., Mingrone, C., Montemagni, C., Rocca, G., \& Rocca, P. (2014). Quality of life in stable schizophrenia: The relative contributions of disorganization and cognitive dysfunction. Schizophrenia Research, 153 (1-3), 196-203. doi: 10.1016/j.schres.2014. 01.013 .

Sibitz, I., Amering, M., Unger, A., Seyringer M.E., Bachmann, A., Schrank. B., Benesch, T., Schulze, B., \& Woppmann. A. (2011). The impact of social network, stigma and empowerment on the quality of life in patients with schizophrenia. European Psychiatry, 26, 28-33. doi: 10.1016/j.eurpsy. 2010.08.010.

Staring, A.B.P, Van der Gaag, M., Van den Berge, M., Duivenvoorden, H.J, \& Mulder, C.L. (2009). Stigma moderates the associations of insight with depressed mood, low selfesteem, and low quality of life in patients with schizophrenia. Schizophrenia Research, 115 (2-3), 363-369. doi: 10.1016/j.schres. 2009.06.015

Stuart, G.W. (2013). Principles and Practice Psychiatric Nursing (10th Ed.). St. Louis: Elsevier/Mosby.

Townsend, M.J. (2011). Essentials of psychiatric mental health nursing: Concepts of care in evidence based practice (5th Ed.). Philadelphia: F.A. Davis Company. 
Üçok, A., Karadayi, G., Emiroğlu, B., \& Sartorius, N. (2013). Anticipated discrimination is related to symptom severity, functionality and quality of life schizofrenia. Psychiatry Research, 209 (3), 333-339. doi: 10.1016/ j.psychres.2013.02.022.

Videbeck, S.L. (2011). Psychiatric mental health nursing (5th Ed.). Philadelphia: Lippincott Williams \& Walkins.

Viertiö, S. (2011). Functional limitations and quality of life in schizophrenia and other psychotic disorder. Finland: National Institute for Health and Welfare.
World Health Organization. (2011). Mental heatlh atlas. Italy: WHO Press.

Yilmaz, E., \& Okanli, A. (2015). The effect of internalized stigma on adherence to treatment in patients with schizofrenia. Archives of Psychiatric Nursing, 29 (5), 297-301. doi: 10.1016/j.apnu.2015.05.006.

Lv, Y., Wolf, A., \& Wang, X. (2013). Experience stigma and self stigma in Chinese patients with Schizophrenia. General Hospital Psychiatry, 35 (1), 83-88. doi: 10.1016/ j.genhosppsych.2012.07.007. 